\title{
New Oligothienyl-imidazo-phenanthroline Chromophores for NLO Applications
}

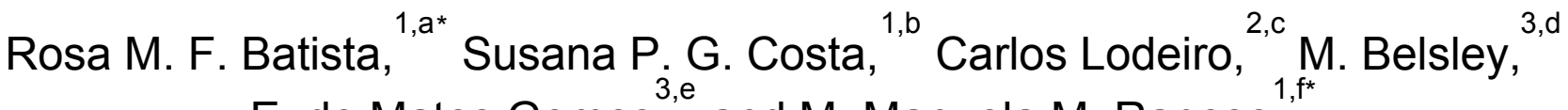 \\ E. de Matos Gomes ${ }^{3, e}$ and M. Manuela M. Raposo
}

${ }^{1}$ Centro de Química, Universidade do Minho, Campus de Gualtar, 4710-057 Braga, Portugal

22REQUIMTE-CQFB, Departamento de Química, FCT-UNL, 2829-516 Monte de Caparica, Portugal

${ }^{3}$ Departamento de Física, Universidade do Minho, Campus de Gualtar, 4710-057 Braga, Portugal

a rosa_batista@quimica.uminho.pt, spc@quimica.uminho.pt, lodeiro@dq.fct.unl.pt,
d ${ }_{\text {e }}^{\text {c }}$ belsley@fisica.uminho.pt, emg@fisica.uminho.pt, mfox@quimica.uminho.pt

Keywords: Phenanthroline, Imidazole, Thiophene, UV-visible spectroscopy, Solvatochromism, Chromophores, Nonlinear optics (NLO), Hyper-Rayleigh scattering technique.

\begin{abstract}
A new series of oligothienyl-imidazo-phenanthrolines 3 were synthesised in good to excellent yields by condensation of 5,6-phenantroline-dione 2 with formyl-thiophene derivatives 1 in the presence of ammonium acetate in glacial acetic acid. Furthermore, their solvatochromism and molecular optical nonlinearities were determined and comparatively studied. The experimental results indicate that phenanthrolines 3 , due to their moderate solvatochromic properties and good optical nonlinearities, could be used as suitable probes for the determination of solvent polarity and as nonlinear optical materials.
\end{abstract}

\section{Introduction}

Donor-acceptor $\pi$-conjugated organic materials have received much attention as they offer many new possibilities for devices combining unique optical, electrical and mechanical properties. In particular, chromophores bearing low aromaticity heterocycles along the conjugation path have been investigated and are considered as the most suitable for these applications. Heterocyclic imidazole based chromophores have received increasing attention due to their distinctive linear and nonlinear optical properties and also due to their excellent thermal stability in guest-host systems and good miscibility with high performance polymers. The imidazole ring can be easily tailored to accommodate functional groups, which allows the covalent incorporation of the NLO chromophores into polyamides leading to NLO side chain polymers [1-10]. New material properties can be achieved when new conjugated systems are composed by different heterocyclic nuclei which allow the fine tuning of important physical and/or photophysical properties. Oligothiophenes behave as very efficient electron relays almost comparable to polyenes, because of the lower resonance energy of thiophene compared to that of benzene, and have been shown to give larger contributions to $\beta$. Oligophenylenes attain a rapid saturation beyond the terphenyl unit, whereas oligothiophenes have a strong tendency to increase $\beta$ with increasing number of thiophene units. Aside from the electron transmission efficiency, another merit of oligothiophenes is their inherent stability from which thiophene-based Donor (D) -Acceptor (A) chromophores should benefit [11]. 
As a result of the optical and conductive properties, conjugated materials containing thiophene and imidazole heterocycles have found many applications including use as hole injection layers in OLED/PLEDs, in flexible light displays, solar cells, flat panel displays, field effect transistors, nonlinear optical materials, sensors, etc. [1-10]. Phenanthroline derivatives have been extensively used as ligands in both analytical and preparative coordination chemistry [12]. Furthermore the planarity and the extension of conjugation of the phenanthroline moiety with imidazole and oligothienyl units leads to an increase of the overall conjugation [13]. Due to the deficiency of electron density on the ring $\mathrm{C}$ atoms, the phenanthroline heterocycle acts also as an acceptor group. Owing to synthetic difficulties, most of the NLO imidazoles developed so far, namely, 2,4,5triaryl(heteroaryl)-imidazoles only possess short conjugation pathways (spacers) such as phenyl, thienyl or thiazolyl. Following our interest in heterocyclic derivatives for optical applications [1421], we report in this communication the synthesis and characterization of the linear and nonlinear optical properties of NLO chromophores 3, containing a functionalized oligothienyl $\pi$ conjugated bridge linked to the imidazo-phenanthroline system, which is original and different from other related reports [1-6].

\section{Results and discussion}

Synthesis. Oligothienyl-imidazo-phenanthrolines 3 were synthesised with different thiophenic substituents at the 2-position of the imidazo-phenanthroline moiety in order to evaluate the effect of the nature of the $\pi$-conjugated bridge on the solvatochromic and nonlinear optical properties of chromophores 3 . Therefore, compounds 3 with either thienyl, bithienyl and terthienyl moieties (substituted with $\mathrm{H}$ or methoxy groups) linked to the imidazo-phenanthroline system, were synthesized in good to excellent yields (76-92\%), by condensation of 5,6-phenanthroline-dione 2 with formyl-thiophene derivatives 1 [14] in the presence of ammonium acetate in refluxing glacial acetic acid [1] for $15 \mathrm{~h}$ (Scheme 1). The structures of the new phenanthrolines 3 were unambiguously confirmed by their analytical and spectral data (Table 1).

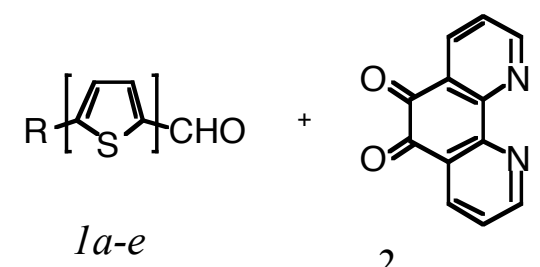

Scheme 1

2
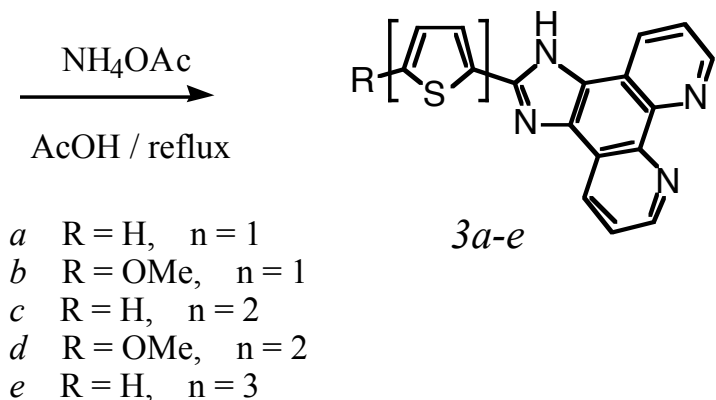

$3 a-e$

$\mathrm{R}=\mathrm{H}, \mathrm{n}=3$

Table 1. Yields, spectroscopic data and linear ${ }^{\mathrm{a}}$ and nonlinear optical data ${ }^{\mathrm{a}}$ for phenanthrolines 3 .

\begin{tabular}{|c|c|c|c|c|c|c|c|c|c|}
\hline Entry & Compd. & $\mathrm{R}$ & $\mathrm{n}$ & $\begin{array}{l}\text { Yield } \\
{[\%]}\end{array}$ & $\begin{array}{c}\text { UV-Vis. } \\
\lambda_{\max }[\mathrm{nm}]^{\mathrm{a}} \\
(\log \varepsilon)\end{array}$ & $\begin{array}{l}\beta / 10^{-30} \\
{[\mathrm{esu}]^{\mathrm{b}}}\end{array}$ & $\begin{array}{c}\beta_{0} / 10^{-30} \\
{[\mathrm{esu}]^{\mathrm{c}}}\end{array}$ & $\begin{array}{l}\text { IR v } \\
{\left[\mathrm{cm}^{-1}\right]}\end{array}$ & $\begin{array}{c}\delta_{\mathrm{H}} \\
{[\mathrm{ppm}]^{\mathrm{d}}}\end{array}$ \\
\hline 1 & $3 a$ & $\mathrm{H}$ & 1 & 90 & $336.5(4.36)$ & 39 & 21 & 3508 & 13.84 \\
\hline 2 & $3 b$ & $\mathrm{OMe}$ & 1 & 92 & $346.0(3.84)$ & 116 & 60 & 3435 & 13.25 \\
\hline 3 & $3 c$ & $\mathrm{H}$ & 2 & 88 & $383.5(4.45)$ & 54 & 23 & 3437 & 13.91 \\
\hline 4 & $3 d$ & $\mathrm{OMe}$ & 2 & 76 & $393.0(4.44)$ & 172 & 68 & 3400 & 13.90 \\
\hline 5 & $3 e$ & $\mathrm{H}$ & 3 & 83 & $411.5(4.43)$ & 319 & 109 & 3426 & not visible \\
\hline 6 & $p \mathrm{NA}$ & --- & --- & --- & 352.0 & 16.9 & 8.5 & --- & --- \\
\hline
\end{tabular}

${ }^{a}$ Experimental hyperpolarizabilities and spectroscopic data measured in dioxane solutions. ${ }^{\mathrm{b}}$ All the compounds are transparent at the $1064 \mathrm{~nm}$ fundamental wavelength. ${ }^{\mathrm{c}}$ Data corrected for resonance enhancement at $532 \mathrm{~nm}$ using the 
two-level model with $\beta_{0}=\beta\left[1-\left(\lambda_{\max } / 1064\right)^{2}\right]\left[1-\left(\lambda_{\max } / 532\right)^{2}\right]$; damping factors not included $1064 \mathrm{~nm} .{ }^{\mathrm{d}}$ For the NH proton of the imidazole ring for compounds $3\left(300 \mathrm{MHz}, \mathrm{DMSO}-\mathrm{d}_{6}\right)$.

$\boldsymbol{U V}$-visible study. Electronic absorption spectra of chromophores 3 in dioxane solutions $\left(10^{-4} \mathrm{M}\right)$ showed an intense lowest energy charge-transfer absorption band in the UV-visible region. The position of this band was strongly influenced by the structure of the compounds, for example by the length of the $\pi$ conjugated bridge and also by the electronic nature of the groups, ( $\mathrm{H}$ or methoxy), that substituted the oligothienyl moiety at the imidazo-phenanthroline system (Table 1). The reason for the red shift in the investigated compound $3 b\left(\lambda_{\max }=346 \mathrm{~nm}\right)$ relative to the unsubstituted thienyl-imidazo-phenanthroline $3 a\left(\lambda_{\max }=336.5 \mathrm{~nm}\right)$ was the strong inductive and conjugative effect of the alkoxy substituent (Table 1, entries 1 and 2 respectively). In general, the stronger the donor and/or acceptor group, the smaller the energy difference between ground and excited states, and the longer the wavelength of absorption. Comparison of the electronic absorption spectra of thienylimidazo-phenanthroline $3 a\left(\lambda_{\max }=336.5 \mathrm{~nm}\right)$ with bithienyl-imidazo-phenanthroline $3 c\left(\lambda_{\max }=\right.$ $383.5 \mathrm{~nm})$ and terthienyl-imidazo-phenanthroline $3 e\left(\lambda_{\max }=411.5 \mathrm{~nm}\right)$ revealed that the increase of the number of thiophene units that constitutes the $\pi$ conjugated bridge caused a dramatic red shift on the charge-transfer band (Figure 1). This observation clearly indicates that the incorporation of thiophene moieties in push-pull compounds enhances their charge-transfer properties. The increase of the $\beta$ values, characteristic of the strength of the NLO response, is accompanied by an increase of the wavelength of the absorption maximum $\lambda_{\max }$ in the UV-visible spectra, i.e. a decrease in the intramolecular charge transfer (ICT) values $[16,22]$.

Figure 1. UV-visible absorption spectra of compounds $3 a, 3 c$ and $3 e$ in dioxane.

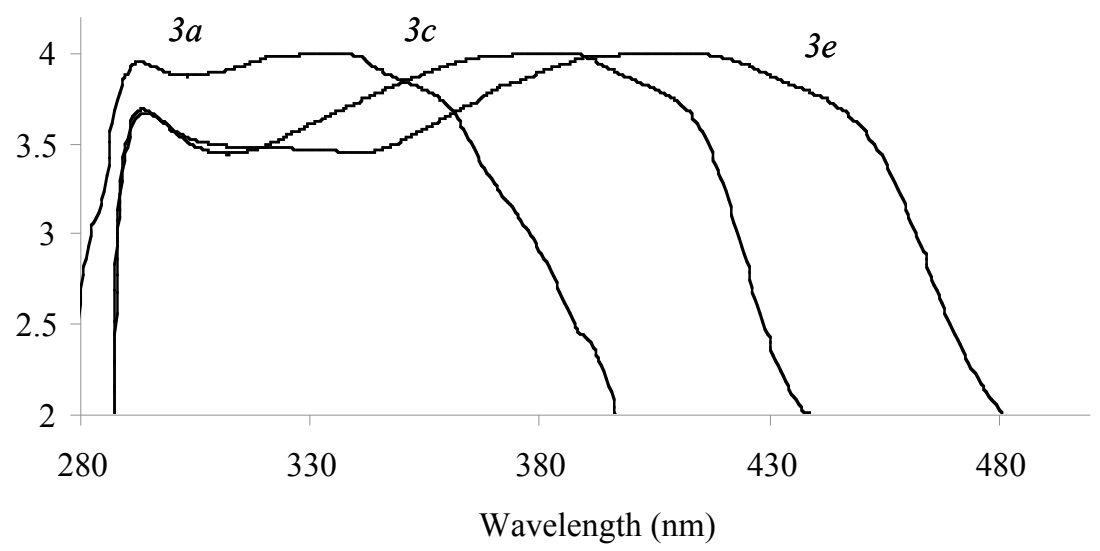

Solvatochromic study. Donor-acceptor substituted oligothiophenes have been known to demonstrate strong solvatochromic behavior [15-16]. In order to investigate if compounds 3 could act as suitable probes for the determination of solvent polarity, we carried out a study of the absorption spectra of compounds 3 in five selected solvents of different solvation character. The wavelength maxima $\lambda_{\max }$ and wavenumber maxima $v_{\max }$ of compounds 3 are listed in Table 2 and were compared with $\pi^{*}$ values for each solvent, determined by Kamlet and Taft [23]. Compounds 3 exhibited positive solvatochromism with respect to their $\mathrm{CT}$ absorption band, that is, the position of the absorption maximum shifted to longer wavelengths as the polarity of the solvent increased due to a great stabilization of the excited state relative to the ground state with the increase of polarity of the solvent. In view of the moderate solvatochromism, the good correlation with $\pi^{*}$ values for the 5 solvents investigated and the long wavelength absorption in the visible range, compounds $3 b\left(\Delta v_{\max }\right.$ $\left.=930 \mathrm{~cm}^{-1}\right) 3 c\left(\Delta v_{\max }=752 \mathrm{~cm}^{-1}\right)$ and $3 e\left(\Delta v_{\max }=821 \mathrm{~cm}^{-1}\right)$ appear to be quite reliable solvent polarity indicating dyes. 
Table 2. Solvatochromic data $\left[\lambda_{\max }(\mathrm{nm})\right.$ and $v_{\max }\left(\mathrm{cm}^{-1}\right)$ of the charge-transfer band] for compounds 3 in various solvents with $\pi^{*}$ values by Kamlet and Taft [23].

\begin{tabular}{|c|c|c|c|c|c|c|c|c|c|c|c|}
\hline \multirow{3}{*}{ Solvent ${ }^{\mathrm{a}}$} & \multirow{3}{*}{$\pi^{*^{\mathrm{b}}}$} & \multicolumn{10}{|c|}{ Compound } \\
\hline & & \multicolumn{2}{|c|}{$3 a$} & \multicolumn{2}{|c|}{$3 b$} & \multicolumn{2}{|c|}{$3 c$} & \multicolumn{2}{|c|}{$3 d$} & \multicolumn{2}{|c|}{$3 e$} \\
\hline & & $\lambda_{\max }$ & $v_{\max }$ & $\lambda_{\max }$ & $v_{\max }$ & $\lambda_{\max }$ & $v_{\max }$ & $\lambda_{\max }$ & $v_{\max }$ & $\lambda_{\max }$ & $v_{\max }$ \\
\hline $\mathrm{EtOH}$ & 0.54 & 333.0 & 30030 & 354.0 & 28248 & 377.0 & 26525 & 389.0 & 25706 & 406.0 & 24630 \\
\hline dioxane & 0.55 & 336.5 & 29717 & 346.0 & 28902 & 383.5 & 26075 & 393.0 & 25445 & 411.5 & 24301 \\
\hline $\mathrm{CHCl}_{3}$ & 0.76 & 337.0 & 29673 & 348.0 & 28736 & 381.0 & 26246 & 391.0 & 25575 & 410.0 & 24390 \\
\hline DMF & 0.88 & 336.0 & 29761 & 356.5 & 28050 & 386.0 & 25906 & 393.0 & 25445 & 419.0 & 23866 \\
\hline DMSO & 1.00 & 337.0 & 29673 & 357.5 & 27972 & 388.0 & 25773 & 394.0 & 25380 & 420.0 & 23809 \\
\hline
\end{tabular}

${ }^{a}$ Solvents used as received. ${ }^{b}$ The correlation coefficient $r$ obtained for the linear solvation energy relationship with $\pi^{*}$ values by Kamlet and Taft was $r=0.9492$ for $3 b$ (without ethanol), $r=0.8987$ for $3 c$ and $r=0.9329$ for $3 e$.

Nonlinear optical study. We used the hyper-Rayleigh scattering (HRS) method [24-25] to measure the first hyperpolarizability $\beta$ of phenanthrolines 3. $p$-Nitroaniline ( $p$ NA) was used as standard [26$27]$ in order to obtain quantitative values. The static hyperpolarizability $\beta_{0}$ values were calculated using a very simple two-level model neglecting damping [28-30]. They are therefore only indicative and should be treated with caution. From Table 1 it is obvious that the increase of the donor strength of the group substituted on the thiophenic or bithiophenic moieties resulted both in redshifted absorption maxima and enhanced $\beta$ values for phenanthrolines $3 b$ and $3 d(\mathrm{R}=\mathrm{OMe})$, compared to derivatives $3 a$ and $3 c(\mathrm{R}=\mathrm{H})$ (Table 1, entries 1-4). Comparison of the $\beta$ values for $3 a$ $\left(39 \times 10^{-30} \mathrm{esu}\right), 3 c\left(54 \times 10^{-30} \mathrm{esu}\right)$ and $3 e\left(319 \times 10^{-30} \mathrm{esu}\right)$ showed that the increase of the number of thiophenic nuclei linked to the imidazo-phenanthroline moiety lead to larger nonlinearities (Table 1, entries 1, 3 and 5 respectively). In comparison with oligophenylenes, oligothiophenes behave as very efficient electron relays almost comparable to polyenes, because of the lower resonance energy of thiophene compared to that of benzene. Oligothiophenes have a strong tendency to increase $\beta$ with increasing number of thiophene units $[11,16]$.

\section{Conclusions}

In summary, we have synthesized new oligothienyl-imidazo-phenanthrolines 3 in good to excellent yields. The solvatochromic and NLO properties of chromophores 3, substituted with different thienyl moieties, functionalized by groups with different electronic character, have been evaluated and it was obvious that the electronic nature of these groups and the number of thiophenic units of the $\pi$ conjugated bridge had significant influence on the solvatochromic and NLO properties. In particular we have shown that phenanthrolines 3 had good molecular nonlinearities especially derivatives $3 d$-e as their $\beta$ values were 10-19 times higher than that of the well known $p$ NA molecule. The experimental results obtained for donor-acceptor compounds 3 indicate that these new heterocyclic materials could find application in nonlinear optics.

\section{Acknowledgements}

Thanks are due to the Portuguese Foundation for Science and Technology (Portugal) for financial support through Centro de Química (UM - project PTDC/QUI/66250/2006, PhD grant to R.M.F. 
Batista SFRH/BD/36396/2007) and Departamento de Física (Universidade do Minho) and Departamento de Química (FCT-UNL) REQUIMTE.

\section{References}

[1] C.R. Moylan, R.D. Miller, R.J. Twieg, K.M. Betterton, V.Y. Lee, T.J. Matray and C. Nguyen: Chem. Mat. Vol. 5 (1993), p. 1499.

[2] X. R. Bu, H. Li, D.V. Derveer and E.A. Mintz: Tetrahedron Lett. Vol. 37 (1996), p. 7731.

[3] J. Santos, E.A. Mintz, O. Zehnder, C. Bosshard, X. R. Bu and P. Günter: Tetrahedron Lett. Vol. 42 (2001), p. 805.

[4] S. Wang, L. Zhao, Z. Xu, C. Wu and S. Cheng: Mater. Lett. Vol. 56 (2002), p. 1035.

[5] W. Wu, C. Ye and D. Wang: ARKIVOK Vol. ii (2003), p. 59.

[6] W. Wu, Z. Zhang and X. Zhang: J. Nonlinear Opt. Phys. Mater. Vol. 14 (2005), p. 61.

[7] K. Feng, L.D. Boni, L. Misoguti, C.R. Mendonça, M. Meador, F.-L. Hsu and X.R. Bu: Chem. Commun. Vol. 10 (2004), p. 1178.

[8] K. Feng, F.-L. Hsu, D.V. DerVeer, K. Bota and X.R. Bu: J. Photochem. Photobiol. A: Chem. Vol. 165 (2004), p. 223.

[9] K. Feng, F.-L. Hsu, K. Bota and X.R. Bu: Microchem. J. Vol. 81 (2005), p. 23.

[10] W.-L. Pan, H.-B. Tan, Y. Chen, D.-H. Mu, H.-B. Liu, Y.-Q. Wan, H.-C Song: Dyes Pigments Vol. 76 (2008), p. 17.

[11] F. Effenberger, F. Wuerthner and F. Steybe: J. Org. Chem. Vol. 60 (1995), p. 2082.

[12] C. Bazzicalupi, A. Bencini, A. Bianchi, L. Borsari, A. Danesi, C. Giorgi, C. Lodeiro, P. Mariani, F. Pina, S. Santarelli, A. Tamayo and B. Valtancolia: Dalton Trans. (2006), p. 4000.

[13] M. Ammamm and P. Bäuerle: Org. Biomol. Chem. Vol. 3 (2005), p. 4143.

[14] M.M.M. Raposo and G. Kirsch: Tetrahedron Vol. 59 (2003), p. 4891.

[15] M.M.M. Raposo, A.M.C. Fonseca and G. Kirsch: Tetrahedron Vol. 60 (2004), p. 4071.

[16] M.M. Oliva, J. Casado, M.M.M. Raposo, A.M.C. Fonseca, H. Hartmann, V. Hernandez and J.T.L. Navarrete J. Org. Chem. Vol. 71 (2006), p.7509.

[17] M.M.M. Raposo, A.M.R.C. Sousa, G. Kirsch, F. Ferreira, M. Belsley, E. Matos Gomes and A. M.C. Fonseca: Tetrahedron Vol. 61 (2005), p. 11991.

[18] M.M.M. Raposo, A.M.R.C. Sousa, G. Kirsch, P. Cardoso, M. Belsley, E. Matos Gomes and A.M.C. Fonseca: Org. Lett. Vol. 8 (2006), p. 3681.

[19] R.M.F. Batista, S.P.G. Costa and M.M.M. Raposo: Tetrahedron Lett. Vol. 45 (2004), p. 2825.

[20] S.P.G. Costa, R.M.F. Batista, P. Cardoso, M. Belsley and M.M.M. Raposo: Eur. J. Org. Chem. Vol. 17 (2006), p. 3938.

[21] R.M.F. Batista, S.P.G. Costa, E. L. Malheiro, M. Belsley and M.M.M. Raposo: Tetrahedron Vol. 63 (2007), p. 4258.

[22] M.G. Hutchins, I. Ferguson, D.J., McGeein, J.O. Morley, J. Zyss and I. Ledoux: J. Chem. Soc. Perkin Trans 2 (1995), p. 171.

[23] M.J. Kamlet, J.-L. M. Abboud, M.H. Abraham and R.W.Taft: J. Org. Chem. Vol. 48 (1983), p. 2877.

[24] K. Clays and A. Persoons: Rev. Sci. Instrum. Vol. 63 (1992), p. 3285.

[25] K. Clays and A. Persoons: Phys. Rev. Lett. Vol. 66 (1991), p. 2980.

[26] C.C.Teng and A.F. Garito: Phys. Rev. B Vol. 28 (1983), p. 6766.

[27] M. Stahelin, D.M. Burland and J.E. Rice: Chem. Phys. Lett. Vol. 191 (1992), p. 245.

[28] J.L. Oudar: J. Chem. Phys. Vol. 67 (1977), p. 446.

[29] J.L. Oudar and D. S. Chemla : J. Chem. Phys. Vol. 66 (1977), p. 2664.

[30] J. Zyss and J.L. Oudar: Phys. Rev. A Vol. 26 (1982), p. 2016. 